Pacific Journal of Mathematics

MODULES WITH SUPPLEMENTS 


\title{
MODULES WITH SUPPLEMENTS
}

\author{
K. VARADARAJAN
}

Let $M$ be an $R$-module and $N \subset M$. Any $H \subset M$ satisfying $H+N=M \ldots \ldots$ (i) and $H^{\prime} \subset H, H^{\prime}+N=M \Rightarrow H^{\prime}=H \ldots$ ... (ii) will be referred to as a supplement of $N$ in $M$. In general $N$ need not have a supplement in $M$. A module $M$ will be said to have property $\left(P_{1}\right)$ if every $N \subset M$ has a supplement in $M$. If for every $A \subset M, N \subset M$ with $A+N=M$, there exists a supplement $H$ of $N$ in $M$ satisfying $H \subset A$, we say that $M$ has property $\left(P_{2}\right)$. Modules with property $\left(P_{2}\right)$ play an important role in our study of dual Goldie dimension. In the present paper we determine the class of rings $R$ with the property that every $M \in R$-mod possesses property $\left(P_{2}\right)$. These ture out to be left perfect rings. Also the results obtained here throw more light on the differences between corank and P. Fleury's spanning dimension.

Introduction. While attempting to dualize the concept of Goldie dimension, Patrick Fleury [3] introduced the class of modules with finite spanning dimension. A module $M$ is said to have finite spanning dimension if for every infinite, strictly decreasing chain $N_{0} \supsetneq N_{1} \supsetneq N_{2} \supsetneq \ldots$... of submodules of $M$, there exists an integer $j$ (depending on the sequence) such that $N_{i}$ is small in $M$ for all $i \geqq j$. A module $H$ is said to be hollow if $H \neq 0$ and any $X \varsubsetneqq H$ is small in $H$. One of the main results of [3] states that any module of finite spanning dimension can be expressed as an irredundant sum $M=\sum_{i=1}^{n} H_{i}$ of finitely many hollow submodules $H_{i}$ of $M$ and that their number $n$ depends only on $M$. This number is referred to as the spanning dimension (abbreviated as $s \cdot d$ ) of $M$. In our earlier paper entitled Dual Goldie dimension [6] we indicated a completely different way of dualizing Goldie dimension and gave ample evidence to show that our approach has distinct advantages over Fleury's approach. Let $k$ be an integer $\geqq 1$. In [6] we defined $M$ to have corank $\geqq k$ if there was an epimorphism $f: M \rightarrow \prod_{i=1}^{k} N_{i}$ with each $N_{i} \neq 0$. For $M \neq 0$ we defined corank $M$ to be $k$ if corank $M \geqq k$, but corank $M \geqq(k+1)$. If corank $M \geqq n$ for all $n \geqq 1$, we set corank $M=\infty$. When $M=0$ we set corank $M=0$. In [6] we showed that the invariant corank had many more desirable properties to be termed dual Goldie dimension than the invariant $s \cdot d$ introduced by $P$. Fleury. Every module with finite spanning dimension possesses preperty $\left(P_{2}\right)$. [3]. In our study of corank also [6], modules with property $\left(P_{2}\right)$ played a special role, 
though the theory of corank works very well for all modules. In the present paper we characterise completely the rings $R$ with the property that every $M \in R$-mod possesses property $\left(P_{2}\right)$.

1. Modules with property $\left(P_{2}\right)$. Throughout this paper all the rings considered are associative rings with an identity element. Unless otherwise mentioned all the modules considered are unitary left modules and all the concepts are left sided concepts. Let $R$ be a ring and $M \in R$-mod. If $M$ satisfies $\left(P_{2}\right)$ it is clear that $M$ satisfies $\left(P_{1}\right)$. In [6] we showed that if every submodule of $M$ has $\left(P_{1}\right)$ then $M$ itself has $\left(P_{2}\right)$. In particular every $M \in R$-mod has $\left(P_{2}\right) \Leftrightarrow$ every $M \in R$-mod has property $\left(P_{1}\right)$.

An epimorphism $\varepsilon: M \rightarrow N$ is said to be minimal if $\operatorname{Ker} \varepsilon$ is small in $M$.

Proposition 1.1. Let $N \subset M$ and $\varepsilon: P \rightarrow M / N$ a minimal epimorphism. Suppose there exists a lift $f: P \rightarrow M$ of $\varepsilon$. Then $H=$ $f(P)$ is a supplement of $N$ in $M$.

Proof. Let $\eta: M / N$ denote the canonical quotient map and $K=$ Ker $\varepsilon$. Then $\eta(H)=\eta \circ f(P)=\varepsilon(P)=M / N$. Hence $H+N=M$. Suppose $H^{\prime} \subset H$ satisfies $H^{\prime}+N=M$. Let $P^{\prime}=f^{-1}\left(H^{\prime}\right)$. Then $f\left(P^{\prime}\right)=H^{\prime}$ and $\varepsilon\left(P^{\prime}\right)=\eta \circ f\left(P^{\prime}\right)=\eta\left(H^{\prime}\right)=M / N$. This yields $P^{\prime}+$ $K=P$. Since $K$ is small in $P$ we get $P^{\prime}=P$. Hence $H^{\prime}=f(P)=H$.

Before proceeding further recall the definition of an $M$-projective module due to G. Azumaya [1].

Definition 1.2. Let $M$ be a fixed $R$-module. An $R$-module $P$ is called $M$-projective, if for any exact sequence $M \stackrel{\varphi}{\rightarrow} M^{\prime \prime} \rightarrow 0$, the sequence $\operatorname{Hom}_{R}(P, M) \stackrel{\varphi^{*}}{\rightarrow} \operatorname{Hom}_{R}\left(P, M^{\prime \prime}\right) \rightarrow 0$ is exact.

Proposition 1.3. Let $A \subset M, N \subset M$ satisfy $A+N=M$. Suppose there exists a minimal epimorphism $\varepsilon: P \rightarrow M / N$ with $P$ an $M$-projective module. Then there exists a supplement $H$ of $N$ in $M$ with $H \subset A$.

Proof. Let $\alpha=\eta / A$ where $\eta: M \rightarrow M / N$ is the canonical quotient map. Then $A+N=M \Rightarrow \alpha(A)=M / N$. Hence $A \stackrel{\alpha}{\rightarrow} M / N \rightarrow 0$ is exact. Since $A \subset M$ and $P$ is $M$-projective, it follows that $P$ is $A$-projective [1]. Hence, there exists a map $f: P \rightarrow A$ with $\alpha \circ f=\varepsilon$. Lemma 1.1 shows that $f(P)=H$ is a supplement of $N$ in $M$. Clearly $H \subset A$. 
Since any projective $R$-module is $M$-projective for any $M \in R$ mod, we get the following as a corollary of Proposition 1.3.

CoROllaRy 1.4. (a) If $R$ is left perfect then every $M \in R$-mod possesses property $\left(P_{2}\right)$.

(b) If $R$ is semi-perfect then every finitely generated $M \in R$ mod possesses property $\left(P_{2}\right)$.

Before proceeding further we state a result of $\mathrm{F}$. Kasch and E. Mares [4] which we need.

Proposition 1.5. (F. Kasch and E. Mares). Let $P$ be a projective module, $N \subset P$. Suppose $H$ is a supplement of $N$ in $P$ and that $H$ itself has a supplement $L$ in $P$. Then $H \cap L=0$, hence $P=H \oplus L$. In particular $H$ is projective.

THEOREM 1.6. The following conditions on a ring $R$ are equivalent.

(1) Every free $R$-module $F$ has property $\left(P_{1}\right)$.

(2) Every $M \in R$-mod has property $\left(P_{2}\right)$.

(3) $R$ is left-perfect.

Proof. (1) $\Rightarrow(3)$. Assuming (1) we will prove that any $M \in$ $R$-mod has a projective cover. Let $F \stackrel{f}{\rightarrow} M \rightarrow 0$ be exact with $F$ free. Let $K=\operatorname{Ker} f$. Let $H$ be a supplement of $K$ in $F$. Since $H$ has a supplement in $F$, from Proposition 1.5 we see that $H$ is projective. Also $H \cap K$ is small in $H$ [4, or Lemma 2.7 of [6]]. It follows that $f \mid H: H \rightarrow M$ is a projective cover of $M$.

$(3) \Rightarrow(2)$ Immediate from Corollary 1.4 (a).

(2) $\Rightarrow(1)$ Trivial.

The arguments used in the above proof also yield the following result:

THEOREM 1.7. The following conditions on a ring $R$ are equivalent.

(1) $R \in R$-mod has property $\left(P_{1}\right)$.

(2) $R$ is semi-perfect.

(3) Every finitely generated $M \in R$-mod has property $\left(P_{2}\right)$.

2. Surjective endomorphisms with small kernels. Let $P$ be a projective module, $N \subset P$. Suppose $N$ has a supplement $H$ in $P$. If $H$ also has a supplement in $P$, then the result of Kasch and Mares asserts that $H$ is a direct summand of $P$. In general, when 
$H$ need not possess a supplement in $P$, we do not know whether $H$ will be projective. The results in the present section throw some light on this question.

It is well-known that any surjective endomorphism $f: M \rightarrow M$ of a noetherian module is an isomorphism. A result of Vasconcelos [7] asserts that if $R$ is a commutative ring and $M$ a finitèly generated module over $R$, then any surjective endomorphism $f: M \rightarrow M$ is an isomorphism. In [5] M. Orzech obtained a generalization of the above results. Let $R$ be a ring, $M \in R$-mod, $N \subset M$. Assume either $M$ is noetherian or that $R$ is commutative and $M$ is finitely generated. Then any epimorphism $f: N \rightarrow M$ is an isomorphism. In this section we will first obtain a useful modification of the above result of Orzech. For any $M \in R$-mod, we denote the set of small submodules of $M$ by $\Gamma(M)$ and partially order $\Gamma(M)$ under inclusion. The class of finitely generated $R$-modules will be denoted by $M(R)$.

Lemma 2.1. Let $M \in R$-mod. Then $\Gamma(M)$ satisfies $a \cdot c \cdot c \Leftrightarrow J(M)$ is noetherian.

Proof. The implication $\Longleftarrow$ follows from the well-known fact that any $N \in \Gamma(M)$ satisfies $N \subset J(M)$. Conversely, suppose $J(M)$ is not noetherian. Let $X_{1} \subsetneq X_{2} \subsetneq X_{3} \subsetneq \cdots \cdots$ be an infinite ascending chain of submodules of $J(M)$. Let $x_{1} \in X_{1}$ and $x_{j} \in X_{j}-X_{j-1}$ for each $j>1$. For any $k \geqq 1$ let $N_{k}=\sum_{j=1}^{k} R x_{j}$. Then $N_{k} \in M(R)$ and $N_{k} \subset J(M)$. Hence $N_{k} \in \Gamma(M)$. It is clear that $N_{1} \varsubsetneqq N_{2} \varsubsetneqq N_{3} \varsubsetneqq \cdots \cdots$. Hence $\Gamma(M)$ fails to satisfy $a \cdot c \cdot c$. This proves the implication $\Longrightarrow$.

LeMma 2.2. Let $M \stackrel{f}{\rightarrow} M^{\prime \prime}$ be an epimorphism with $\operatorname{Ker} f$ small in $M$. Then $f(J(M))=J\left(M^{\prime \prime}\right)$.

Proof. Since $f(J(M)) \subset J\left(M^{\prime \prime}\right)$, to prove the equality $f(J(M))=$ $J\left(M^{\prime \prime}\right)$ we have only to show that $f^{-1}\left(J\left(M^{\prime \prime}\right)\right) \subset J(M)$. Let $y \in J\left(M^{\prime \prime}\right)$. Then $R y$ is small in $M^{\prime \prime}$. Since $f: M \rightarrow M^{\prime \prime}$ is an epimorphism with Ker $f$ small in $M$, it follows that $f^{-1}(R y)$ is small in $M$ and hence $f^{-1}(R y) \subset J(M)$. This proves $f^{-1}\left(J\left(M^{\prime \prime}\right)\right) \subset J(M)$.

Proposition 2.3. Let $M \in R$-mod, $N \subset M$ and $f: N \rightarrow M$ an epimorphism with Ker $f$ small in $N$. Assume that either $J(M)$ is noetherian or that $R$ is commutative and $J(M)$ is finitely generated. Then $f$ is an isomorphism.

Proof. Let $K=\operatorname{Ker} f$. Then $K \subset J(N) \subset J(M)$. By Lemma 2.2, $g=f \mid J(N): J(N) \rightarrow J(M)$ is an epimorphism. From Orzech's 
result we see that $g$ is an isomorphism. Hence Ker $g=\operatorname{Ker} f=$ $K=0$. This proves that $f: N \rightarrow M$ is an isomorphism.

Let $R$ be any ring and $E$ any injective module over $R, N \subset E$ and $L$ a relative complement of $N$ in $E$ (namely $N \cap L=0, N \cap$ $L^{\prime} \neq 0$ for any $\left.L \varsubsetneqq L^{\prime} \subset E\right)$. Since $E$ is injective we can assume that the injective hull $E(L)$ of $L$ is a submodule of $E$. From $N \cap$ $L=0$ we get $N \cap E(L)=0$. Hence $L=E(L)$. Thus any relative complement in $E$ is injective. If $P$ is a projective $R$-module, $K \subset P$ admitting a supplement $H$ in $P$, in general we do not know whether $H$ will be projective. The following is a result in this direction. For any $M \in R$-mod let $S(M)=\{H \mid H \subset M, H$ a supplement of some $N \subset M$ \}.

Proposition 2.4. Let $P$ be a projective $R$ module and $H \in S(P)$. If either $J(H)$ is noetherian or $R$ is commutative and $J(H)$ is finitely generated over $R$ then $H$ is a direct summand of $P$ and hence $H$ is projective.

Proof. Let $H$ be a supplement of $N$ in $P$ and $\eta: P \rightarrow P / N$ denote the canonical quotient map. From Lemma 2.7 of [6] we see that $H \cap N$ is small in $H$. From $H+N=P$ we get $\eta(H)=$ $P / N$. Let $\alpha=\eta \mid H$. Then $H \stackrel{\alpha}{\rightarrow} P / N \rightarrow 0$ is exact. Since $P$ is projective, there exists a $\varphi: P \rightarrow H$ with

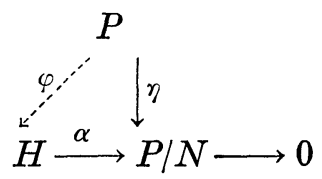

commutative. From $\alpha(\varphi(H))=\eta(H)=P / N$ we get $\varphi(H)+\operatorname{Ker} \alpha=$ $H$. But $\operatorname{Ker} \alpha=H \cap N$. Since $H \cap N$ is small in $H$ we get $\varphi(H)=$ $H$. Also $\operatorname{Ker} \varphi \subset \operatorname{Ker} \eta$. If $f=\varphi \mid H: H \rightarrow H$, then $\operatorname{Ker} f \subset N \cap H$ and $f$ is an epimorphism. From Proposition 2.3 we see that $f$ is an isomorphism. Let $\theta=j \circ f^{-1}: H \rightarrow P$ where $j$ is the inclusion of $H$ in $P$. Then $\varphi \circ \theta=\theta \circ j \circ f^{-1}=f \circ f^{-1}=I d_{H}$. Thus $\theta$ is a splitting of $\varphi$. If $h=f^{-1} \circ \varphi: P \rightarrow H$ we have $h \circ j=f^{-1} \circ \varphi \circ j=f^{-1} \circ f=I d_{H}$. This proves that $H$ is a direct summand of $P$.

\section{Corank versus spanning dimension.}

REMARKS.

(1) In [5] we proved that if $s \cdot d M<\infty$, then corank $M=s \cdot d M$. Also in the same paper we proved that if $R$ is any local ring, and 
$M=R \times R$ in $R$-mod then corank $M=2$. But if $R$ is nonartinian, then $s \cdot d M=\infty$. Since any local ring is semi-perfect, it follows form Corollary $1.4(\mathrm{~b})$ that $M$ satisfies property $\left(P_{2}\right)$.

(2) For any $M$ with property $\left(P_{2}\right)$ and having corank $M=n<$ $\infty$ we have proved the following two assertions in [6].

(a) $M=\sum_{i=1}^{n} H_{i}$ an irredundant sum with each $H_{i}$ hollow.

(b) If $M=\sum_{g=1}^{k} H_{j}^{\prime}$ is an irredundant sum with each $H_{j}^{\prime}$ hollow then $k=n$.

Thus P. Fleury's main result [Theorem 3.1 of [3]] was extended by us to the class of modules $M$ with corank $M<\infty$ and satisfying $\left(P_{2}\right)$. The example $M=R \times R$ in $R$-mod, with $R$ a nonartinian local ring shows that the above class is strictly larger than the class of modules with finite spanning dimension.

(3) Let $S(M)=\{H / H \subset M, H$ a supplement of some $N \subset M\}$. If $M$ is a module with property $\left(P_{2}\right)$, we proved in [5] that corank $M=\operatorname{Sup}\left\{k \mid\right.$ there exists a strict increasing chain $H_{0} \subsetneq H_{1} \varsubsetneqq \cdots \varsubsetneqq H_{k}$ of length $k$ with each $\left.H_{i} \in S(M)\right\}$. For the example $M=R \times R$ in $R$-mod with $R$ a nonartinian local ring we have corank $M=2$. Thus there exist strict increasing chains of supplement submodules in $M$ of length 2 and not more. However $s \cdot d M=\infty$. Thus in this example $\operatorname{Sup}\left\{k \mid\right.$ there exists a strict increasing chain $H_{0} \varsubsetneqq \cdots$ $\subseteq H_{k}$ with each $\left.H_{i} \in S(M)=2<s \cdot d M\right\}$. This is one instance where corank is better behaved than spanning dimension.

\section{REFERENCES}

1. G. Azumaya, M-projective and M-injective modules, (unpublished).

2. H. Bass, Finitistic dimension and a homological generalization of semiprimary rings, Trans. Amer. Math. Soc., 95 (1960), 466-488.

3. P. Fleury, A note on dualizing Goldie dimension, Canad. Math. Bull., 17 (1974), 511-517.

4. F. R. Kasch and E. A. Mares, Eine Kennzeichnung semi-perfecter moduln, Nagoya Math. J., 27 (1966), 525-529.

5. M. Orzech, Onto endomorphisms are isomorphisms, Amer. Math. Monthly, 78 (1971), 357-362.

6. K. Varadarajan, Dual Goldie Dimension, Communications in Algebra, 7 (1979), 565-610.

7. W. V. Vasconcelos, On finitely generated flat modules, Trans. Amer. Math. Soc., 138 (1960), 505-512.

Received August 10, 1978. Research done when the author was partially supported by NRC grant A8225.

The University of CALGary

Calgary, Alberta, Canada 


\section{PACIFIC JOURNAL OF MATHEMATICS}

\section{EDITORS}

Donald BABBITT (Managing Editor)

University of California

Los Angeles, CA 90024

HUGo RossI

University of Utah

Salt Lake City, UT 84112

C. C. MOORE and ANDREW OGG

University of California

Berkeley, CA 94720

\section{J. DuGUNDJI}

Department of Mathematics

University of Southern California

Los Angeles, CA 90007

R. FINN and J. Milgram

Stanford University

Stanford, CA 94305

ASSOCIATE EDITORS
E. F. BECKENBACH
B. H. NeumanN
F. WOLF
K. YoSHIDA

\section{SUPPORTING INSTITUTIONS}

\author{
UNIVERSITY OF BRITISH COLUMBIA \\ CALIFORNIA INSTITUTE OF TECHNOLOGY \\ UNIVERSITY OF CALIFORNIA \\ MONTANA STATE UNIVERSITY \\ UNIVERSITY OF NEVADA, RENO \\ NEW MEXICO STATE UNIVERSITY \\ OREGON STATE UNIVERSITY \\ UNIVERSITY OF OREGON
}

\author{
UNIVERSITY OF SOUTHERN CALIFORNIA \\ STANFORD UNIVERSITY \\ UNIVERSITY OF HAWAII \\ UNIVERSITY OF TOKYO \\ UNIVERSITY OF UTAH \\ WASHINGTON STATE UNIVERSITY \\ UNIVERSITY OF WASHINGTON
}

The Supporting Institutions listed above contribute to the cost of publication of this Journal, but they are not owners or publishers and have no responsibility for its content or policies.

Mathematical papers intended for publication in the Pacific Journal of Mathematics should be in typed form or offset-reproduced, (not dittoed), double spaced with large margins. Please do not use built up fractions in the text of the manuscript. However, you may use them in the displayed equations. Underline Greek letters in red, German in green, and script in blue. The first paragraph or two must be capable of being used separately as a synopsis of the entire paper. Please propose a heading for the odd numbered pages of less than 35 characters. Manuscripts, in triplicate, may be sent to any one of the editors. Please classify according to the scheme of Math. Reviews, Index to Vol. 39. Supply name and address of author to whom proofs should be sent. All other communications should be addressed to the managing editor, or Elaine Barth, University of California, Los Angeles, California, 90024.

50 reprints to each author are provided free for each article, only if page charges have been substantially paid. Additional copies may be obtained at cost in multiples of 50 .

The Pacific Journal of Mathematics is issued monthly as of January 1966. Regular subscription rate: $\$ 84.00$ a year (6 Vols., 12 issues). Special rate: $\$ 42.00$ a year to individual members of supporting institutions.

Subscriptions, orders for numbers issued in the last three calendar years, and changes of address should be sent to Pacific Journal of Mathematics, P.O. Box 969, Carmel Valley, CA 93924, U.S.A. Older back numbers obtainable from Kraus Periodicals Co., Route 100, Millwood, NY 10546.

PUBLISHED BY PACIFIC JOURNAL OF MATHEMATICS, A NON-PROFIT CORPORATION

Printed at Kokusai Bunken Insatsusha (International Academic Printing Co., Ltd.). 8-8, 3-chome, Takadanobaba, Shinjuku-ku, Tokyo 160, Japan.

Copyright (C) 1979 by Pacific Journal of Mathematics Manufactured and first issued in Japan 


\section{Pacific Journal of Mathematics}

\section{Vol. 82 , No. 2 \\ February, 1979}

Krishnaswami Alladi and Paul Erdős, On the asymptotic behavior of large prime

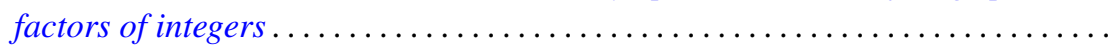

Alfred David Andrew, A remark on generalized Haar systems in $L_{p}$,

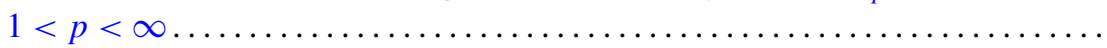

John M. Baker, A note on compact operators which attain their norm . . ........

Jonathan Borwein, Weak local supportability and applications to

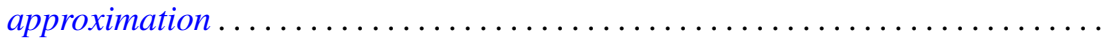

Tae Ho Choe and Young Soo Park, Wallman's type order compactification ........

Susanne Dierolf and Ulrich Schwanengel, Examples of locally compact

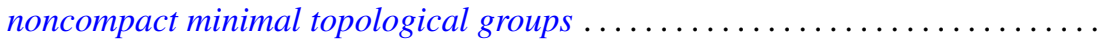

Michael Freedman, A converse to (Milnor-Kervaire theorem) $\times R$ etc. . . . . . . .

George Golightly, Graph-dense linear transformations ..................

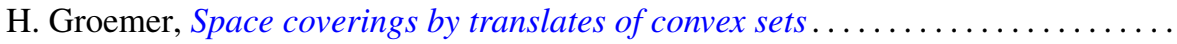

Rolf Wim Henrichs, Weak Frobenius reciprocity and compactness conditions in

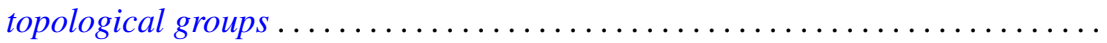

Horst Herrlich and George Edison Strecker, Semi-universal maps and universal

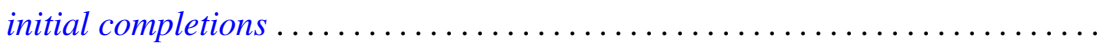

Sigmund Nyrop Hudson, On the topology and geometry of arcwise connected,

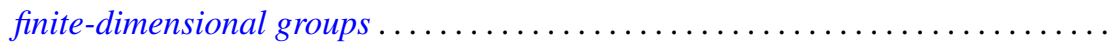

K. John and Václav E. Zizler, On extension of rotund norms. II .............

Russell Allan Johnson, Existence of a strong lifting commuting group of transformations. II.

Bjarni Jónsson and Ivan Rival, Lattice varieties covering the smallest nonmodular variety

Grigori Abramovich Kolesnik, On the order of Dirichlet L-functions .

Robert Allen Liebler and Jay Edward Yellen, In search of nonsolvable groups of

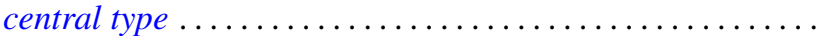

Wilfrido Martínez T. and Adalberto Garcia-Maynez Cervantes, Unicoherent plane Peano sets are $\sigma$-unicoherent ...

M. A. McKiernan, General Pexider equations. I. Existence of injective

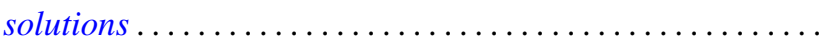

M. A. McKiernan, General Pexider equations. II. An application of the theory of webs.

Jan K. Pachl, Measures as functionals on uniformly continuous functions . .

Lee Albert Rubel, Convolution cut-down in some radical convolution algebras ...

Peter John Slater and William Yslas Vélez, Permutations of the positive integers

with restrictions on the sequence of differences. II . . .

Raymond Earl Smithson, A common fixed point theorem for nested spaces ....

Indulata Sukla, Generalization of a theorem of McFadden .... . . .

Jun-ichi Tanaka, A certain class of total variation measures of analytic measures.

Kalathoor Varadarajan, Modules with supplements .............. 